International Journal of Current Advanced Research

ISSN: O: 2319-6475, ISSN: P: 2319 - 6505, Impact Factor: SJIF: 5.995

Available Online at www.journalijcar.org

Volume 6; Issue 5; May 2017; Page No. 3734-3739

DOI: http://dx.doi.org/10.24327/ijcar.2017.3739.0359

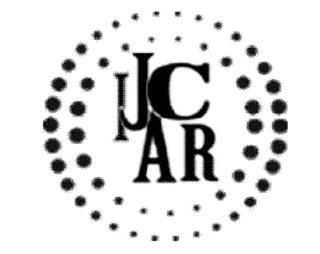

Research Article

\title{
THE EFFECT ON COMPETENCY MAPPING IN MANUFACTURING INDUSTRY ASSEMBLY VICINITY WITH REFERENCE TO KRISHNAGIRI DISTRICT TAMILNADU-A STUDY
}

\author{
Santhoshkumar $\mathbf{R}^{*}$ and Hemal Raj**
}

Marian International Institute of Management, Kuttikannam, Peermade Post, Idukki District, Kerala, India

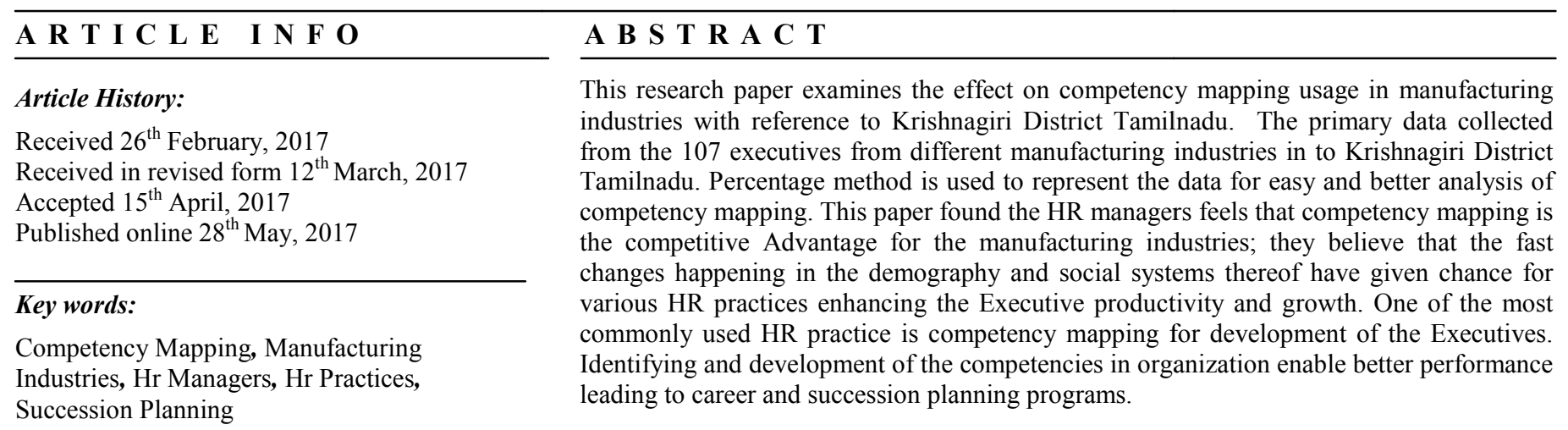

Copyright $@ 2017$ Santhoshkumar $\mathbf{R}$ andHemal Raj. This is an open access article distributed under the Creative Commons Attribution License, which permits unrestricted use, distribution, and reproduction in any medium, provided the original work is properly cited.

\section{INTRODUCTION}

A competency model is a descriptive tool that identifies the competencies needed to operate in a specific role within job, occupation, organization, or industry. Competency Mapping is a process of identifying the competencies required, to successfully perform a particular job or role or a set of tasks at a given point of time. It consists of mapping the given job into constituent roles and identifying the competencies needed to perform the job successfully but competencies vary from job to job, department to department. For different departments and also people in different Levels, these competencies have separate weightage. Accordingly, Competency Mapping rates the employee skills in the way of assessing the potential, capability, and behavior aspect of executives against the need of a particular role. It is about identifying a person's job competencies in areas like Functional competencies and Behavioral competencies against the present level in each competency. Large organizations may use some method of this technique to understand the best form of each worker or to combine the strengths of different executives, to produce the highest quality work i.e., required level of competencies expected by the organization and for building strong working relationship within the organization. Competency of the people has to be continuously monitored and enhanced in congruence with the business plan. Individuals may also find that this type of assessment can help them prepare for the

*Corresponding author: Santhoshkumar R

Marian International Institute of Management,

Kuttikannam, Peermade Post, Idukki District, Kerala, India career change or advance in the specific job field. In view of the recent developments of liberalization and globalization, every organization has to achieve excellence to become global. Competence development will play a pivotal role in this regard.

\section{REVIEW OF LITERATURE}

Milind Kotwal (2014) had already studied the competency mapping under the title "Model and method for Competency Mapping and Assessment". As per their objective, Competency mapping helps to develop objective system for recruitments, Promotions, training and development, and performance diagnostics. And also they are offering consultancy services in the following areas: organizational diagnostic studies, corporate and strategic planning, performance management and performance appraisal, competency mapping and assessment, customer satisfaction studies. They have studied the competency mapping in relation with job description.

According to Boyatzis (2013) adopted the term competency an "underlying characteristic of an individual that is casually related to effective or superior performance in a job". He identified that there were 19 generic competencies that outstanding managers tend to have. He clubbed those 19 generic management competencies into five distinct clusters as goal and action management, leadership, human resource management, directing subordinates and focus on others. 
Deb (2012) stated that Human Resource Manager has to help all other functions to continuously upgrade their own systems, processes, practices, and skills by providing relevant internal and external training and expertise. He also explained that to keep upgrading the competencies of the human resources functionaries at all levels, in the formulation and implementation of human resources structures, systems, policies and practices dealing with individuals and collectives, as well as their dynamically updated knowledge of the business environment, others functions challenges and emerging human resources needs. Gaspar (2012) found that Competency based selection method is healthy, structured and comprehensive. Candidates are evaluated on the competencies they need to demonstrate, when inducted into the organization. Performance management competency system diagnoses the future training and development needs of the Executives and it helps the HR executives to assist Executives in decisions like promotions and transfers. Gilbert (2012) define competence as the state of being competent refers to having the ability to consistently produce the results (the worthy outcomes of behavior) that are required for the most efficient and effective achievement of the larger organizational goals. McClelland (2011) presented data that traditional achievement and intelligence scores may not be able to predict job success and what is required is to profile the exact competencies required to perform a given job effectively and measure them using a variety of tests. He argued that traditional intelligence tests, as well as proxies such as scholastic grades, failed to predict job performance. According to Hogg B (2010) "competencies are the characteristics of a manager that lead to the demonstration of skills and abilities, which result in effective performance within an occupational area. Competency also embodies the capacity of transfer skills and abilities from one area to another"

Table 1 Beat of Competency mapping in a variety of point

\begin{tabular}{cc}
\hline Variables for the Study & Variables for the Study \\
\hline People Leadership & Decision making \\
Team work and & Productivity and \\
collaboration & maximization \\
Business Excellence & Quality focus \\
Problem solving & Safety awareness \\
\hline
\end{tabular}

Source: Secondarydata-Review of literature

\section{Objectives of the Study}

- To arrive the Behavioral/Functional competencies required for each and every role in the production area of the manufacturing industries.

- Create a map of competencies for each section / Hierarchy in manufacturing industries.

- Consolidate the maps and provide it to the "Competency Library" of the manufacturing industries

- Getting the Assessment done for each of the role holder against the relevant mapping to find out his level in each competency

- Make an analysis to find out the gap and consolidate it to use in Training Need Identification.

\section{METHODOLOGY}

This study is containing both primary and secondary data. The sampling size of this study is 107 . The data collected from the
HR Manager Manufacturing Industries Krishnagir district TamilNadu. Descriptive research has been used for the study, because the aims of the descriptive research are to describe accurately the characteristics of particular individual situation or group and to determine the frequency of occurrence of such events. The method of data collection used primary data and secondary data. The statistical tools are used to obtain findings and information in logical sequence from the data collected. Percentage of competency Level $=($ Sum of Executives in each level)/ (No of Executives * No of competency)*100.

\section{Data Analysis}

Table No: 1 Shows the Required Competencies of the Section Head in Assembly

Table No 1 Competency Mapping For Chassis Assembly

\begin{tabular}{cccccccccc}
\hline \multicolumn{10}{c}{ Section Heads } \\
\hline \multicolumn{8}{c}{ Competency Assessment Form } \\
\hline \multicolumn{10}{c}{ Rated on 5 point scale } \\
\hline S NO & NO & CG & PL & TW/COLL & BE & DM & P,Q and DCO & SA \\
\hline 1 & 1001 & 25 & 4 & 3 & 3 & 4 & 3 & 3 & 4 \\
2 & 1002 & 26 & 3 & 3 & 3 & 3 & 4 & 3 & 4 \\
\hline
\end{tabular}

Source: Primary Data

Table No 2 Competency Mapping For Cab Trim

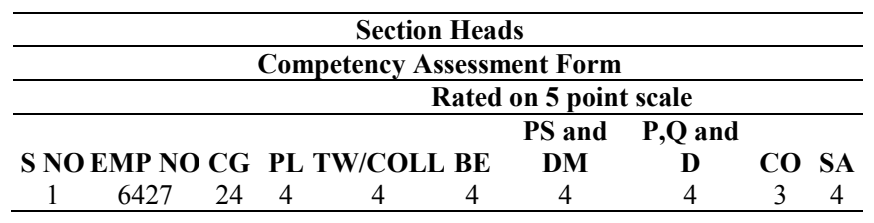

Source: Primary Data

Table No 3 Competency Mapping For Frame

Section Heads

Competency Assessment Form

Rated on 5 point scale

S NO EMP NO CG PL TW/COLL BEPS and DMP,Q and DCO SA \begin{tabular}{llllllllll}
\hline 1 & 7081 & $24 \mathrm{~A}$ & 4 & 4 & 4 & 3 & 3 & 4 & 3 \\
\hline
\end{tabular}

Source: Primary Data

Table No: 2 Shows the Required Competencies of the Front Line Executives in Assembly

Table No 1 Competency Mapping Assessment For Cab Trim

\begin{tabular}{cccccccccc}
\hline \multicolumn{8}{c}{ Front Line Executives } \\
\hline \multicolumn{8}{c}{ Competency Assessment Form } \\
\hline \multicolumn{8}{c}{ Rated on 5 point scale } \\
\hline S NO & EMP NO & CG & BE PS and DM COMM & PM QF & DA SA & CM \\
\hline 1 & 6811 & 22 & 2 & 3 & 3 & 1 & 2 & 3 & 3 \\
2 & 6145 & 22 & 2 & 3 & 3 & 2 & 3 & 3 & 3 \\
3 & 6977 & 22 & 1 & 2 & 2 & 2 & 2 & 3 & 3 \\
4 & 6166 & 22 & 2 & 3 & 3 & 2 & 3 & 3 & 3 \\
5 & 9580 & 22 & 2 & 3 & 3 & 2 & 3 & 3 & 3 \\
\hline
\end{tabular}

Source: Primary Data

Table No 2 Competency Mapping For Chassis Assembly

\begin{tabular}{cccccccccc}
\hline \multicolumn{10}{c}{ Front Line Executives } \\
\hline \multicolumn{10}{c}{ Competency Assessment Form } \\
\hline S NO & EMP NO & CG & BE & PS and DM & COMM & PM & QF & DA & SA \\
1 & 2003 & 22 & 5 & 4 & 4 & 5 & 5 & 5 & 4 \\
2 & 2004 & 22 & 4 & 4 & 4 & 4 & 4 & 5 & 4 \\
3 & 2005 & 22 & 4 & 3 & 4 & 5 & 4 & 5 & 4 \\
4 & 2006 & 22 & 5 & 4 & 4 & 5 & 4 & 5 & 4 \\
5 & 2007 & 22 & 3 & 3 & 4 & 4 & 4 & 4 & 4 \\
6 & 2008 & 23 & 3 & 3 & 4 & 4 & 4 & 4 & 4 \\
7 & 2009 & 23 & 4 & 4 & 4 & 4 & 4 & 4 & 4 \\
8 & 2010 & 23 & 3 & 3 & 3 & 4 & 4 & 4 & 4 \\
9 & 2011 & 23 & 3 & 3 & 3 & 4 & 4 & 4 & 4 \\
10 & 2012 & $24 \mathrm{~A}$ & 4 & 4 & 4 & 4 & 4 & 4 & 4 \\
11 & 2013 & $24 \mathrm{~A}$ & 4 & 4 & 4 & 4 & 4 & 4 & 4 \\
\hline
\end{tabular}

Source: Primary Data 
Table No 3 Competency Mapping For Axle Assembly

\begin{tabular}{cccccccccc}
\hline \multicolumn{8}{c}{ Competency Assessment Form } \\
\hline \multicolumn{8}{c}{ Rated on 5 point scale } \\
\hline \multicolumn{10}{c}{ CM } \\
\hline S NO & EMP NO & CG & BE & PS and DM COMM & PM & QF & DA & SA \\
\hline 1 & 2001 & 22 & 3 & 2 & 2 & 3 & 3 & 3 & 2 \\
2 & 2002 & 22 & 3 & 2 & 3 & 2 & 3 & 3 & 2 \\
3 & 2003 & 23 & 3 & 3 & 3 & 3 & 3 & 3 & 3 \\
4 & 2004 & 24 & 4 & 3 & 3 & 3 & 3 & 3 & 2 \\
5 & 2005 & $24 \mathrm{~A}$ & 4 & 3 & 3 & 3 & 3 & 3 & 3 \\
\hline
\end{tabular}

Source: Primary Data

Table No 4 Competency Mapping For Frame Assembly

\begin{tabular}{|c|c|c|c|c|c|c|c|c|c|}
\hline \multicolumn{10}{|c|}{ Front Line Executives } \\
\hline \multicolumn{10}{|c|}{ Competency Assessment Form } \\
\hline & & & \multicolumn{7}{|c|}{ Rated on 5 point scale } \\
\hline S NO & EMP NO & CG & $\mathbf{B E}$ & PS and & DMCOMM & PM & QF & DA & SA \\
\hline 1 & 5001 & 22 & 2 & 2 & 2 & 2 & 3 & 3 & 3 \\
\hline 2 & 5008 & 23 & 3 & 3 & 3 & 3 & 3 & 4 & 3 \\
\hline 3 & 5010 & 23 & 4 & 4 & 3 & 3 & 4 & 4 & 3 \\
\hline
\end{tabular}

Table No 3 Shows the Required Competencies of the Front Line Executive In Cab Paint

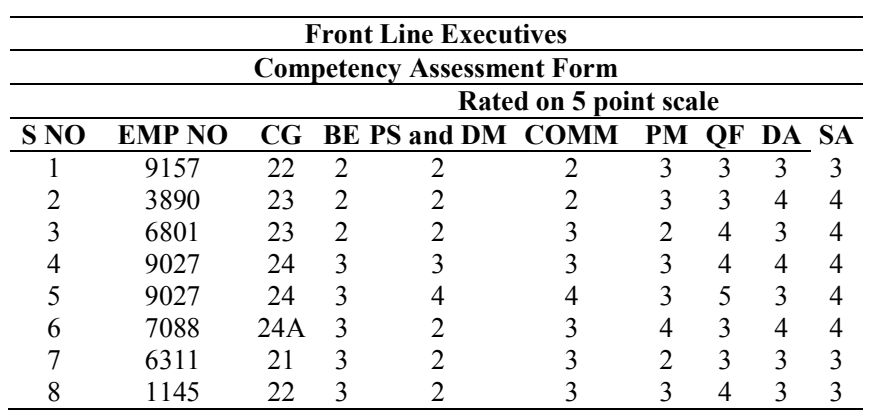

Source: Primary Data

Table No 4 Shows the Required Competencies of the Section Head In Cab Weld

\begin{tabular}{ccccccccc}
\hline \multicolumn{8}{c}{ Cection Heads } \\
\hline \multicolumn{8}{c}{ Competency Assessment Form } \\
\hline \multicolumn{8}{c}{ Rated on 5 point scale } \\
\hline S NO & EMP NO & CG PL TW/COLL BE PS and DM P,Q and D CO SA \\
1 & 6070 & $24 \mathrm{~A}$ & 4 & 4 & 4 & 4 & 4 & 3 \\
\hline
\end{tabular}

Source: Primary Data

Table No 5 Shows the Required Competencies of the Front Line Executives in Cab Weld

\begin{tabular}{cccccccccc}
\hline \multicolumn{10}{c}{ Front Line Executives } \\
\hline \multicolumn{10}{c}{ Rated on 5 point scale } \\
\hline \multicolumn{10}{c}{ Competency Assessment Form } \\
\hline S NO & EMP NO & CG & BE PS and DM COMM & PM & QF & DA SA \\
1 & 6244 & 22 & 1 & 2 & 1 & 2 & 2 & 2 & 3 \\
2 & 6311 & 22 & 2 & 3 & 3 & 3 & 3 & 3 & 3 \\
3 & 6174 & 23 & 2 & 2 & 2 & 3 & 3 & 3 & 3 \\
4 & 6205 & 23 & 2 & 2 & 2 & 3 & 3 & 3 & 3 \\
\hline
\end{tabular}

Source: Primary Data

Table No 6 Shows the Required Competencies of the Section Head In Maintenance

\begin{tabular}{|c|c|c|c|c|c|c|c|c|c|}
\hline \multicolumn{10}{|c|}{ Section Heads } \\
\hline \multicolumn{10}{|c|}{ Competency Assessment Form } \\
\hline \multicolumn{10}{|c|}{ Rated on 5 point scale } \\
\hline S NO & EMP NO & CG & PL & TW/COLL & BE I & PS and & DM PM & $\mathrm{CO}$ & $\mathbf{S A}$ \\
\hline 1 & 6105 & 26 & 3 & 3 & 2 & 3 & 4 & 3 & 4 \\
\hline 2 & 6098 & 25 & 3 & 3 & 3 & 4 & 4 & 4 & 4 \\
\hline 3 & 6404 & 26 & 3 & 3 & 3 & 4 & 4 & 4 & 5 \\
\hline 4 & 6193 & 26 & 3 & 3 & 3 & 3 & 4 & 4 & 5 \\
\hline 5 & 6601 & 26 & 3 & 3 & 3 & 4 & 4 & 4 & 4 \\
\hline 6 & 6104 & 26 & 4 & 3 & 4 & 4 & 3 & 3 & 4 \\
\hline
\end{tabular}

Table No 7 Shows the Required Competencies of the Front Line Executives in Maintenance

\begin{tabular}{|c|c|c|c|c|c|c|c|c|c|}
\hline \multicolumn{10}{|c|}{ Front Line Executives } \\
\hline \multicolumn{10}{|c|}{ Competency Assessment Form } \\
\hline \multicolumn{10}{|c|}{ Rated on 5 point scale } \\
\hline S NO & EMP NO & $\mathbf{C G}$ & $\mathbf{B E}$ & PS and DM & COMM & $\mathbf{P M}$ & $\mathbf{Q F}$ & DA & $\mathbf{S A}$ \\
\hline 1 & 8904 & 22 & 3 & 2 & 2 & 3 & 2 & 4 & 3 \\
\hline 2 & 8920 & 23 & 3 & 3 & 3 & 4 & 4 & 4 & 3 \\
\hline 3 & 8963 & $24 \mathrm{~A}$ & 3 & 3 & 3 & 4 & 4 & 4 & 3 \\
\hline 4 & 4106 & $24 \mathrm{~A}$ & 3 & 3 & 3 & 3 & 3 & 4 & 4 \\
\hline 5 & 5346 & 21 & 2 & 2 & 2 & 3 & 2 & 2 & 4 \\
\hline 6 & 9654 & 21 & 2 & 2 & 2 & 3 & 3 & 3 & 3 \\
\hline 7 & 9543 & 22 & 2 & 2 & 2 & 2 & 2 & 2 & 2 \\
\hline 8 & 7195 & 22 & 3 & 3 & 3 & 3 & 4 & 4 & 5 \\
\hline 9 & 6589 & 22 & 3 & 3 & 2 & 3 & 3 & 3 & 3 \\
\hline 10 & 8932 & 23 & 3 & 2 & 3 & 4 & 3 & 4 & 4 \\
\hline 11 & 2459 & 23 & 3 & 4 & 3 & 4 & 3 & 4 & 3 \\
\hline 12 & 9854 & 23 & 2 & 2 & 3 & 3 & 3 & 3 & 3 \\
\hline 13 & 1012 & 23 & 3 & 3 & 2 & 4 & 3 & 4 & 4 \\
\hline 14 & 3467 & 23 & 3 & 3 & 3 & 4 & 3 & 4 & 4 \\
\hline 15 & 9010 & 24 & 2 & 2 & 3 & 3 & 3 & 3 & 3 \\
\hline 16 & 1249 & 24 & 2 & 2 & 2 & 3 & 3 & 3 & 3 \\
\hline
\end{tabular}

Source: Primary Data

Table No 8 Shows the Required Competencies of the Front Line Executives In Smp

\begin{tabular}{|c|c|c|c|c|c|c|c|c|c|}
\hline \multicolumn{10}{|c|}{ Front Line Executives } \\
\hline \multicolumn{10}{|c|}{ Competency Assessment Form } \\
\hline \multicolumn{10}{|c|}{ Rated on 5 point scale } \\
\hline S NO & EMP NO & CG & $\mathbf{B E}$ & PS and & DM COMM & PM & QF & DA & SA \\
\hline 1 & 6109 & 21 & 2 & 2 & 2 & 3 & 3 & 4 & 4 \\
\hline 2 & 9141 & 23 & 2 & 3 & 4 & 4 & 3 & 4 & 3 \\
\hline 3 & 9102 & 23 & 2 & 2 & 2 & 3 & 4 & 3 & 4 \\
\hline
\end{tabular}

Source: Primary Data

Table No 9 Shows the Required Competencies of the Section Head In Lcv-Cab Trim

\begin{tabular}{|c|c|c|c|c|c|c|c|}
\hline \multicolumn{8}{|c|}{ Section Heads } \\
\hline \multicolumn{8}{|c|}{ Competency Assessment Form } \\
\hline & & & & ated & n 5 po & int scale & \\
\hline S NO & EMP NO & CG PL & TW/COLL & BE & $S$ and & DM P,Q an & d D COSA \\
\hline 1 & 6078 & 253 & 3 & 3 & 2 & 2 & 23 \\
\hline 2 & 6129 & 252 & 2 & 2 & 3 & 2 & 22 \\
\hline
\end{tabular}

Source: Primary Data

Table No 10 Shows the Required Competencies of the Front Line Executives in Lcv-Cab Trim

\begin{tabular}{|c|c|c|c|c|c|c|c|c|c|}
\hline \multicolumn{10}{|c|}{ Front Line Executives } \\
\hline \multicolumn{10}{|c|}{ Competency Assessment Form } \\
\hline & & & \multicolumn{7}{|c|}{ Rated on 5 point scale } \\
\hline S NO & EMP NO & CG & BE & PS and DM & COMM & PM & QF & DA & $\mathbf{S A}$ \\
\hline 1 & 6280 & 21 & 2 & 2 & 2 & 2 & 2 & 3 & 3 \\
\hline 2 & 8274 & $24 \mathrm{~A}$ & 4 & 4 & 3 & 4 & 3 & 4 & 3 \\
\hline
\end{tabular}

Table No 11 Shows the Required Competencies of the Section Head In Lcv-Cab Weld

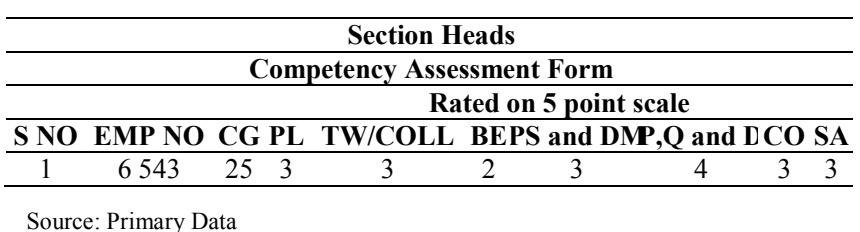


Table No 12 Shows the Required Competencies of the Front Line Executive in Lcv-Cab Weld

\begin{tabular}{cccccccccc}
\hline \multicolumn{10}{c}{ Front Line Executives } \\
\hline \multicolumn{10}{c}{ Competency Assessment Form } \\
\hline Rated on 5 point scale \\
\hline 1 & 6405 & 21 & 2 & 2 & 2 & 4 & 4 & 4 & 3 \\
2 & 6406 & 22 & 2 & 2 & 2 & 4 & 3 & 3 & 3 \\
3 & 1148 & 24 & 3 & 3 & 4 & 2 & 2 & 2 & 3 \\
4 & 1148 & 24 & 3 & 2 & 3 & 3 & 3 & 3 & 2 \\
\hline \multicolumn{10}{c}{ Source: Primary Data }
\end{tabular}

Table No 13 Shows the Required Competencies of the Front Line Executive in Lcv-Chassis Assembly

\begin{tabular}{cccccccccc}
\hline \multicolumn{10}{c}{ Front Line Executives } \\
\hline \multicolumn{10}{c}{ Competency Assessment Form } \\
\hline \multicolumn{10}{c}{ Rated on 5 point scale } \\
\hline S NO & EMP NO & CG & BE PS and DM COMM & PM & QF & DA SA \\
\hline 1 & 6234 & 22 & 2 & 2 & 2 & 3 & 3 & 4 & 4 \\
2 & 6316 & 22 & 2 & 2 & 2 & 4 & 4 & 4 & 4 \\
3 & 6406 & 22 & 1 & 1 & 2 & 4 & 3 & 2 & 3 \\
4 & 6413 & 22 & 2 & 2 & 2 & 4 & 3 & 3 & 3 \\
5 & 9174 & 22 & 3 & 3 & 2 & 4 & 3 & 4 & 4 \\
6 & 9195 & 22 & 3 & 3 & 3 & 4 & 3 & 3 & 3 \\
7 & 9197 & 22 & 3 & 3 & 2 & 4 & 3 & 3 & 3 \\
8 & 9197 & 22 & 4 & 4 & 4 & 5 & 5 & 4 & 4 \\
9 & 9198 & 22 & 4 & 4 & 3 & 4 & 5 & 4 & 4 \\
10 & 9198 & 22 & 3 & 3 & 2 & 4 & 3 & 4 & 3 \\
11 & 1145 & 22 & 2 & 3 & 3 & 3 & 3 & 3 & 4 \\
12 & 6427 & 23 & 4 & 5 & 4 & 5 & 5 & 4 & 4 \\
13 & 6814 & 23 & 4 & 4 & 3 & 5 & 4 & 4 & 4 \\
14 & 6814 & 23 & 3 & 4 & 3 & 3 & 4 & 3 & 3 \\
15 & 6497 & 24 & 4 & 4 & 4 & 5 & 5 & 4 & 4 \\
\hline
\end{tabular}

Source: Primary Data

Table No 14 Shows the Required Competencies of the For Section Head in Pdi And Vts

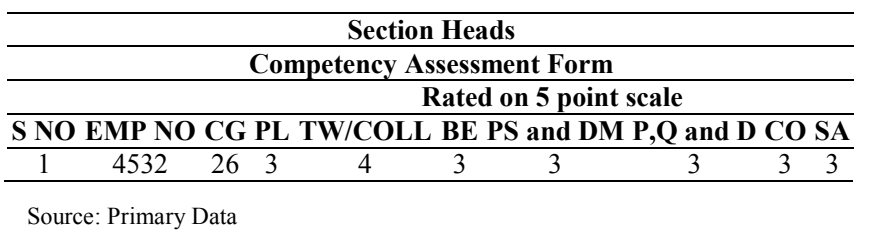

Table No 15 Shows the Required Competencies of The Front Line Executive In Pdi And VTS

\begin{tabular}{cccccccccc}
\hline \multicolumn{10}{c}{ Front Line Executives } \\
\hline \multicolumn{10}{c}{ Competency Assessment Form } \\
\hline \multicolumn{10}{c}{ Rated on 5 point scale } \\
\hline S NO & EMP NO & CG & BE PS and DM COMM & PM & QF & DA & SA \\
\hline 1 & 6297 & 22 & 4 & 4 & 4 & 4 & 4 & 4 & 4 \\
2 & 6330 & 22 & 4 & 4 & 4 & 4 & 4 & 4 & 4 \\
3 & 6170 & 22 & 4 & 4 & 4 & 4 & 4 & 4 & 4 \\
4 & 1302 & 23 & 4 & 4 & 4 & 4 & 4 & 4 & 4 \\
5 & 9142 & 23 & 4 & 4 & 4 & 4 & 4 & 4 & 4 \\
6 & 6423 & 23 & 4 & 4 & 4 & 4 & 4 & 4 & 4 \\
7 & 6439 & 24 & 4 & 4 & 4 & 4 & 4 & 4 & 4 \\
8 & 9074 & 24 & 4 & 4 & 4 & 4 & 4 & 4 & 4 \\
9 & 6140 & 21 & 3 & 3 & 3 & 3 & 4 & 3 & 3 \\
\hline
\end{tabular}

Source: Primary Data

PL-PeopleLeadership, TW/COLL-TeamWork/Collaboration, BE-Business Excellence, PS\&DM-Problem Solving and Decision Making, P,Q and DProductivity Maximization, Quality Focus, and Delivery Adherence, Co-Cost Optimization, SA-Safety Awareness,EMP NO-Employee Sample Number

\section{RESULT AND DISCUSSION}

\section{Behavioral Skills}

a. Behavioral competency are common for the Section Head cadre a common findings has been arrived i.e., In People Leadership -one executive falls in level 2, nine executives falls in level 3 and five executives falls in level 4; In Teamwork / Collaboration- one executive falls in level 2, ten executives falls in level 3 and four executives falls in level 4; In Business Excellence -three executives falls in level 2, eight executives falls in level 3 and four executives falls in level 4; one executive falls in level 2, six executives falls in level 3 and seven executives falls in level 4.

b. Behavioral competency are common for the Front Line Executive cadre a common findings has been arrived i.e., In Business Excellence- two Executives are in level 1 ,twenty four executives are in level 2, thirty one executives are in level 3, twenty two executives are in level 4, two executives are in level 5; In Problem solving and Decision making - one executives are in level 1, twenty seven are in level 2 , twenty nine executives are in level 3, twenty three executives are in level 4, one executives are in level 5; In Communication twenty four executives are in level 2 , thirty four executives are in level 3, twenty three executives are in level 4.

\section{Functional skills}

\section{Section head}

1. Functional competency of the Section Head cadre in the Assembly's common finding has been arrived i.e., In Productivity Maximization, Quality Focus, and Delivery Adherence- two executives are in level 2 , three executives are in level 3, two executives are in level 4; In Cost Optimization- two executives are in level 2, four executives are in level 3, one executives are in level 4; In Safety Awareness- one executives are in level 1 , three executives are in level 3 , three executives are in level 4 .

2. Functional competency of the Section Head cadre in the Maintenance common finding has been arrived i.e., In Productivity Maximization- one executives are in level 3, five executives are in level 4; In Cost Optimization- two executives are in level 3, four executives are in level 4; In Safety Awareness- four executives are in level 4, two executives are in level 5.

3. Functional competency of the Section Head cadre in the Cab Weld common finding has been arrived i.e., In Productivity Maximization, Quality Focus, and Delivery Adherence- two executives are in level 4; In Cost Optimization- two executives are in level 3; In Safety Awareness- one executives are in level 3, one executive are in level 4.

\section{Front Line Executive}

1. Functional competency of the Front Line Executive cadre in the Assembly's common finding has been arrived i.e., In Productivity Maximization- one executives are in level 1 , seven executives are in level 2 , ten executives are in level 3 , twenty five executives are in level 4, seven executives are in level 5; In Quality Focus Three Executives are in level 2, nineteen executives are in level 3, twenty three Executives are in level 4, five Executives are in level 5; In Delivery Adherence- one executives are in level 2, eighteen executives are in level 3, twenty seven executives are in level 4, four executives are in level 5; In Safety Awareness- three executives are in level 2, nineteen 
executives are in level 3 , twenty six executives are in level 4.

2. Functional competency of the Front Line Executive cadre in the Cab Paint common finding has been arrived i.e., In Productivity Maximization- two executives are in level 2, five executives are in level 3, one executives are in level 4; In Quality Focus four executives are in level 3, three executives are in level 4, one executives are in level 5; In Delivery Adherence- five executives are in level 3,three executives are in level 4; In Safety Awareness- three executives are in level 3, five executives are in level 4.

3. Functional competency of the Front Line Executive cadre in the Cab Weld common finding has been arrived i.e., In Productivity Maximization- two executives are in level 2, four executives are in level 3, two executives are in level 4; In Quality Focus- two executives are in level 2, two executives are in level 3, four executives are in level 4; In Delivery Adherencetwo executives are in level 2, two executives are in level 3, four executives are in level 4; In Safety Awareness- one executives are in level 2, six executives are in level 3.

4. Functional competency of the Front Line Executive cadre in the Maintenance common finding has been arrived i.e., In Productivity Maximization- one executives are in level 2, nine executives are in level 3, six executives are in level 4; In Quality Focus- three executives are in level 2, ten executives are in level 3 ,three executives are in level 4; In Delivery Adherence- two executives are in level 2, five executives are in level 3, nine executives are in level 4; In Safety Awareness- two executives are in level 2, nine executives are in level 3 , five executives are in level 4, one executives are in level 5.

5. Functional competency of the Front Line Executive cadre in the SMP common finding has been arrived i.e., In Productivity Maximization- two executives are in level 3, one executives are in level 4; In Quality Focus- two executives are in level 3, one executives are in level 4; In Delivery Adherence- one executives are in level 3, two executives are in level 4; In Safety Awareness- one executives are in level 3, two executives are in level 4

\section{Recommendations}

- Section Head is being a higher position; the desired level of Behavioral Competency's is 4 . So those in Level 2 and 3 may have to be trained. Considering the severity of lower levels in different competencies, 'Business Excellence' and 'Team Work and Collaboration' may be given priority in the training calendar.

- For Front Line Executive, the desired level of Behavioral Competency's is 3. So those in Level 1 and 2 may have to be trained. Considering the severity of lower levels especially in Level 1, among different competencies, 'Business Excellence' may be given priority in the training calendar.

- Section Head is being a higher position; the desired level of Functional Competency's is 4 . So those in Level 1, 2 and 3 may have to be trained and For Front Line Executives, the desired level of
Functional Competency's is 3. So those in Level 1 and 2 may have to be trained

- The Training calendar for the next year should incorporate the gaps identified in level 1 and 2, 3 giving in the findings

- For all the training programs based on the desired levels for each of the competency training plan need to be arrived however if the Gap between individual level and desired level is more than 1 his competency level need to be assessed after 6 months to decide further training to the next level or retrained at the same level

\section{CONCLUSION}

The organization can utilize the competency mapping and the gap identified to improve their training need identification process The HR department should be sensitized about the need for competency mapping \& this process of competency mapping should be carried out in the organization on the regular basis both for the benefit of employees and for the organization. In today's changing globally environment, it could be greatly beneficial to ensure that training programs are conducted on various competencies in order to meet new standards and to update knowledge to perform to the satisfaction. The management may effectively use their competency mapping for improving the training platform which is designed based on the outcome of competency gap analysis. This can also be used for job rotation, career development and Succession planning. Last but not the least, as a cost saving measure as well as creating a sense of loyalty, the management may think in terms of developing internal trainer, employees who got the requisite skills and have excelled may be identified and developed as trainer.

\section{References}

1. Peter Cheese et.,al, (2008), The Talent Powered Organization, Kogan Page Limited Publications, 2008 Edition.

2. Prof. Rupali Kumar (2007), War For , Journal: Management Effigy, Volume II, Issue II, July to Dec 2007, Shri Vaishnav Institute of Management, Indore, pp.84-92(9).

3. Sriddar S Preetham (2007), Managing Talent, HRD News letter, Volume 123, Issue 4, July 2007.

4. William J Rothwell, The Strategic Development of Competency mapping.

5. Yan Shen and Douglas T. (Tim) Hall (2009) When Expatriates Explore Other Options: Retaining Talent Through Greater Job Embeddedness And Repatriation Adjustment, Journal of HRM, Volume 48, Number 5, Sep-Oct 2009, John Wiley \& Sons Publications at the University of Michigan, pp.793-816(22).

6. Anderson, Cushing (2009), Succession Planning Gains Momentum, Chief Learning Officer, March. http://www.clomedia.com/

7. BCG and World Federation of Personnel Management Associations. 2008.

8. http://www.bcg.com/impact_expertise/publication/files /Aligning_Talent_for_Global_Advantage_Sep_07.pdf, Retrieved on Aug. 1, 2009.

9. Burns, R.B. \& Burns, R.A. 2008. Business Research Methods and Statistics using SPSS, sage Publications Ltd., London. 
10. Branham, F.L. 2000. Keeping The People Who Keep You In Business: 24 Ways to Hang On To Your Most Valuable Talent, AMACOM, NY
11. Bryan, L.L. 2007. The New Metrics of Corporate Performance: Profit Per Employees, The Mckinsey Quarterly, Feb.

12. Candidate Resource, Inc, Understanding The Achiever. http://www.whytest.biz / Understanding Achiever.htm - Retrieved on August 30, 2009.

\section{How to cite this article:}

Santhoshkumar R and Hemal Raj (2017) 'The Effect On Competency Mapping In Manufacturing Industry Assembly Vicinity With Reference To Krishnagiri District Tamilnadu-A Study', International Journal of Current Advanced Research, 06(05), pp. 3734-3739. DOI: http://dx.doi.org/10.24327/ijcar.2017.3739.0359

$* * * * * * *$ 